\title{
EVS24
}

Stavanger, Norway, May 13-16, 2009

\section{Modelling the RESS: Describing Electrical Parameters of Batteries and Electric Double-Layer Capacitors through Measurements}

\author{
ing. B. Verbrugge ${ }^{1}$, ing. Y. Heremans ${ }^{2}$, ing. F. Van Mulders ${ }^{3}$, ir. H. Culcu ${ }^{4}$, dr. ir. P. Van den \\ Bossche $^{5}$, prof. dr. ir. J. Van Mierlo ${ }^{6}$ \\ ${ }^{\prime}$ ing. Bavo Verbrugge, Building Z / Pleinlaan 2 / 1050 Brussel / BELGIUM, bavo.verbrugge@vub.ac.be \\ ${ }^{2}$ ing. Yves Heremans, Building Z / Pleinlaan 2 / 1050 Brussel / BELGIUM \\ ${ }^{3}$ ing. Frederik Van Mulders, Building Z / Pleinlaan 2 / 1050 Brussel / BELGIUM \\ ${ }^{4}$ ir. Hasan Culcu, Building Z / Pleinlaan 2 / 1050 Brussel / BELGIUM \\ ${ }^{5} d r$. ir. Peter Van den Bossche, Building Z / Pleinlaan 2 / 1050 Brussel / BELGIUM \\ ${ }^{6}$ prof. dr. ir. Joeri Van Mierlo, Building Z / Pleinlaan 2 / 1050 Brussel / BELGIUM
}

\begin{abstract}
Being able to predict the behaviour of Rechargeable Energy Storage Systems (RESS) such as batteries and Electric Double-Layer Capacitors (EDLC) relies on the models used to represent them. Research on the development and enhancement of these models is performed on two tracks: on one hand by defining the model topology, where a trade-off is sought between the reduction of components in the model equivalent scheme and the ability of the model to describe all potential system behaviour and, on the other hand by improving the method of calculating the magnitudes of the different components in the model. The storage devices examined in this paper are divided in two groups, electrochemical devices and electrical double layer capacitors. The first group consists of lead-acid, lithium, Ni-Cd and Ni-MH batteries. The second group comprises of Electric Double-Layer Capacitors (EDLC). For every model used to describe a battery or EDLC, different techniques are implemented to calculate the magnitude of the components. The work presented in this paper will elaborate to the calculating method used in NREL's FreedomCAR test-manual adapted to fit different battery- and EDLC models. This method consists of an iterative approach to the equations of the model using data gathered from performing tests on the battery or supercapacitor. Validation of the models obtained through this calculating method will be done by performance tests on the storage devices. As the models of batteries and supercapacitors are a key aspect in the simulation software for hybrid-vehicles more accurate models result in more accurate simulations. These simulation programs depend upon the underlying component models, the data generated by which determines the accuracy of the program's data-output. The availability of reliable storage RESS models will thus be a key element in to allow overall vehicle modelling.
\end{abstract}

Keywords: Battery Model, EDLC, Simulation 


\section{Introduction}

Modelling of batteries and EDLC's (Electrochemical Double Layer Capacitors) is carried out by acquiring data from tests performed on these energy storage devices. The data are acquired using the RESS test-facility called Digatron. Figure 1 shows the test-facility.

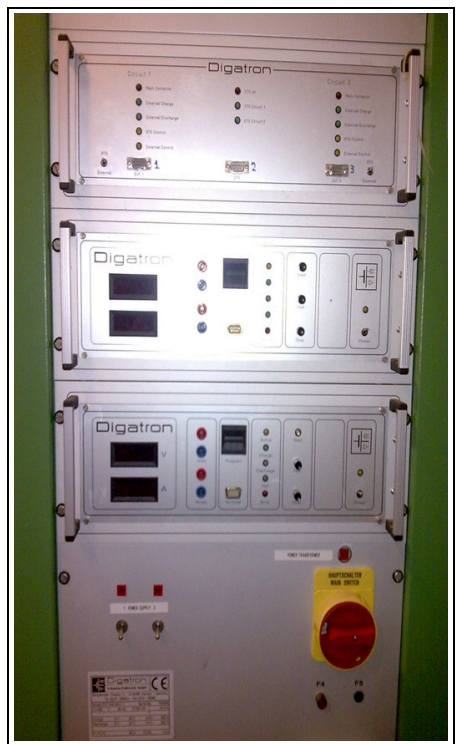

Figure 1: Front view of the Digatron test-facility

The test-facility comprises of two test-circuits, giving the opportunity to test different energy storage devices at the same time. All essential data is logged onto the hard-drive of a connected computer, witch also runs the software for controlling the Digatron. Tests-sequences for storage devices are inputted in the program (BTS-600), compiled and loaded in the memory of the Digatron.

\section{Reference test and calculation method}

\subsection{NREL test method}

The test method described in the FreedomCAR Battery Test Manual (appendix D) [1] consists of a test cycle (Hybrid Pulse Power Characterisation test, HPPC-test), a battery model for pulse load conditions and a calculation method for defining the magnitudes of the model's components. This calculation method is used as a reference method for other models within the paper and future work. The test cycle, model and the calculation method are described in 2.2, 2.3 and 2.4 respectively.

\subsection{Test cycle (HPPC-test)}

The HPPC-test cycle (Figure 2) is performed to derive the battery's dynamic power capabilities during a 10sec discharge and $10 \mathrm{sec}$ regenerative load. By performing this test on different levels of discharge (every $10 \%$ ), the characteristic of the internal resistance and polarization resistance lead to a function of the State of Charge ( $\mathrm{SoC})$. Figure 3 shows the initial start phase of the HPPC-test, whereas Figure 4 shows the complete HPPC-test.

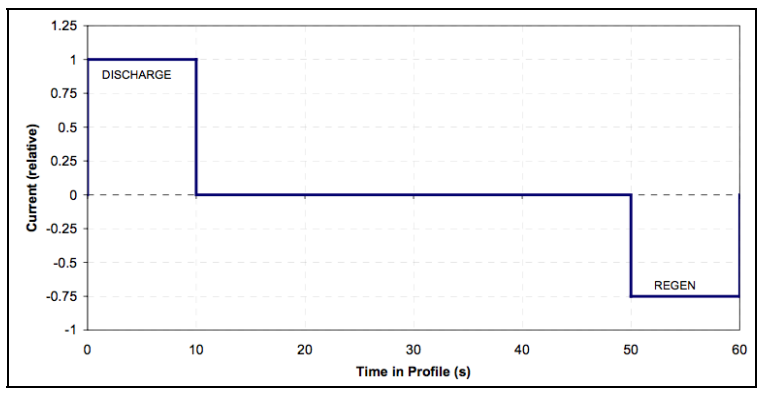

Figure 2: HPPC-test profile (source: [1])

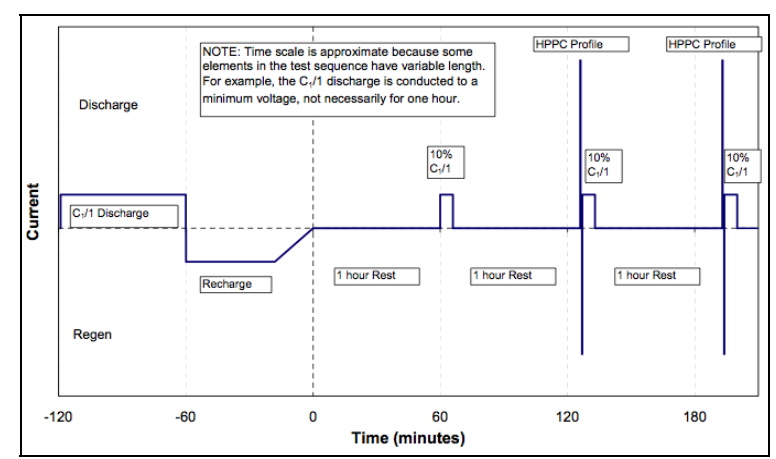

Figure 3: HPPC-test initial phase (source: [1])

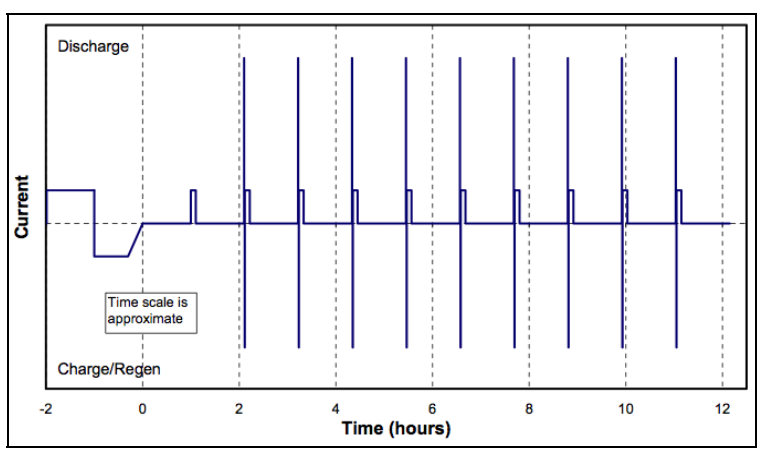

Figure 4: HPPC-test complete (source: [1]) 


\subsection{Scheme}

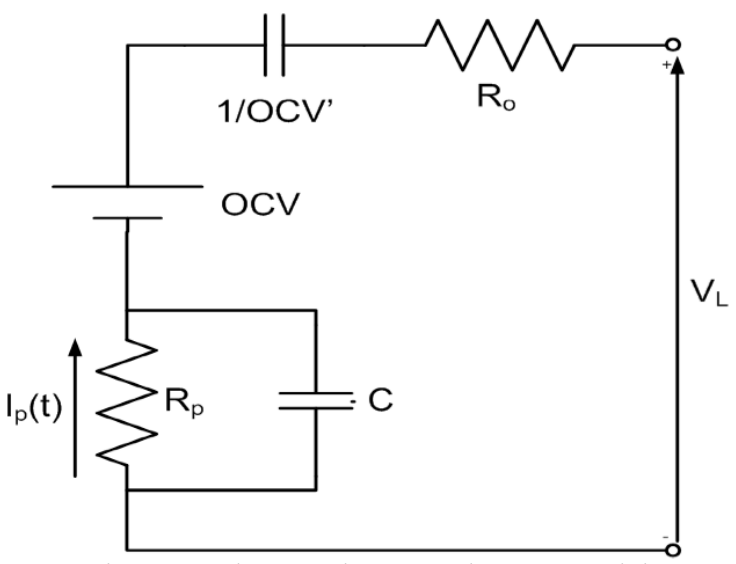

Figure 5: The FreedomCAR battery model

Describing every complex non-linear parameter over the life-span of the battery using available test data is difficult, therefore NREL linearized the battery model. Figure 5 represents the scheme used in the FreedomCAR test-manual [1]; this model is commonly referred to "The FreedomCAR Model". Five components, each representing a different aspect of the battery, are needed to make up the model. An overview of these different aspects is given by Table 1. Table 1 also includes the used abbreviations for current and voltage within the model.

Table1: Parameters of the model (source: [1])

\begin{tabular}{|c|c|c|}
\hline $\mathrm{OCV}$ & $\begin{array}{l}\text { An ideal voltage source that } \\
\text { represents "open circuit" } \\
\text { battery voltage }\end{array}$ & {$[\mathrm{V}]$} \\
\hline $\mathrm{R}_{\mathrm{o}}$ & $\begin{array}{l}\text { Battery internal "ohmic" } \\
\text { resistance }\end{array}$ & {$[\Omega]$} \\
\hline $\mathrm{R}_{\mathrm{p}}$ & $\begin{array}{l}\text { Battery internal } \\
\text { "polarization" resistance } \\
\text { ( e.g., due to concentration } \\
\text { gradients) }\end{array}$ & {$[\Omega]$} \\
\hline $\mathrm{C}$ & Shunt capacitance around $R_{P}$ & {$[\mathrm{~F}]$} \\
\hline$\tau$ & $\begin{array}{l}\text { Polarization time constant, } \tau \\
=\mathrm{R}_{\mathrm{p}}{ }^{*} \mathrm{C}\end{array}$ & [sec] \\
\hline $\mathrm{I}_{\mathrm{L}}$ & Battery load current & {$[\mathrm{A}]$} \\
\hline $\mathrm{I}_{\mathrm{P}}$ & $\begin{array}{l}\text { Current through polarization } \\
\text { resistance }\end{array}$ & {$[\mathrm{A}]$} \\
\hline $\mathrm{V}_{\mathrm{L}}$ & Battery terminal voltage & {$[\mathrm{V}]$} \\
\hline $1 / \mathrm{OCV}^{\prime}$ & $\begin{array}{l}\text { A capacitance that accounts } \\
\text { for the variation in open } \\
\text { circuit voltage with the time } \\
\text { integral of load current } \mathrm{I}_{\mathrm{L}} \text {. } \\
\mathrm{OCV}^{\prime} \text { is not usually equal to } \\
\text { the slope of } \mathrm{V}_{\mathrm{L}} \text { measured } \\
\text { open circuit vs. battery state } \\
\text { of charge }\end{array}$ & $\begin{array}{l}\mathrm{V} / \mathrm{A} \\
\mathrm{sec}]\end{array}$ \\
\hline
\end{tabular}

\subsection{Calculation method}

The Kirchhoff Voltage Law (KVL) describing the FreedomCAR model - or $\mathrm{PNGV}^{1}$ model - is given by equation 1 . This equation forms the basis upon which the "battery parameter estimator spreadsheet" by NREL is constructed. In this spreadsheet the load-current $\left(\mathrm{I}_{\mathrm{L}}\right)$ and the timevector - as recorded in the test-cycle - are used as input-variables to calculate the battery's terminal voltage $\left(\mathrm{V}_{\mathrm{L}, \mathrm{i}(\mathrm{est} t)}\right)$. Since these recordings are made at discrete points in time, the load-current $I_{L}$, polarization-current $I_{P}$ and terminal voltage $V_{L}$ are accommodated with an $i$ in subscript. Equation 5 is the discrete form of equation 1. In order to calculate $I_{P}$ the differential equation 2 is used. A solution of this differential equation in discrete form is given by equation 3; this equation is implemented in the battery parameter spreadsheet to calculate $I_{P}$ in the discrete recording points $i$.

$$
\begin{aligned}
& V_{L}=O C V-O C V^{\prime}\left(\int I_{L} \cdot \mathrm{dt}\right)-R_{0} \cdot I_{L}-R_{P} \cdot I_{P} \\
& d I_{P} / d t=\left(I_{L}-I_{P}\right) / \tau \\
& I_{P, i}=\left(1-\frac{1-e^{-\frac{\Delta t}{\tau}}}{\frac{\Delta t}{\tau}}\right) \times I_{L, i} \\
& +\left(\frac{1-e^{-\frac{\Delta t}{\tau}}}{\frac{\Delta t}{\tau}}-e^{-\frac{\Delta t}{\tau}}\right) \times I_{L, i-1} \\
& \quad+e^{-\frac{\Delta t}{\tau}} \times I_{P, i-1} \\
& \left(\Sigma I_{L} \Delta t\right)_{i}=\left(\Sigma I_{L} \Delta t\right)_{i-1}+\left(I_{L, i}+I_{L, i-1}\right) \cdot\left(t_{i}-t_{i-1}\right) / 2 \\
& V_{L, i(\text { est })}=O C V_{0}+O C V^{\prime} \cdot\left(\Sigma I_{L} \Delta t\right)_{i}-I_{L, i} \cdot R_{0}-I_{P, i} \cdot R_{P}
\end{aligned}
$$

$\mathrm{V}_{\mathrm{L}}$ is the terminal voltage and is therefore measurable. The recorded data of $\mathrm{V}_{\mathrm{L}}$ can be used to calculate the difference between measured and estimated terminal voltage. $\Delta \mathrm{V}_{\mathrm{i}}$ is the difference between the measured voltage $\mathrm{V}_{\mathrm{L}, \mathrm{i}}$ and the calculated (estimated) voltage $\mathrm{V}_{\mathrm{L}, \mathrm{i}(\text { est) }}$. This difference is used as an indicator for the accuracy of the estimated terminal voltage (equation 6 shows the difference in voltage in a discrete manner). In the "battery parameter estimator spreadsheet" the difference between these two voltages is plotted.

$$
\Delta V_{i}=V_{L, i(e s t)}-V_{L, i}
$$

The spreadsheet uses an estimate for $\tau$ to calculate

1 Partnership for a New Generation of Vehicles 
$\mathrm{V}_{\mathrm{L}, \mathrm{i} \text { (est) }}$. After calculating $\mathrm{V}_{\mathrm{L}, \mathrm{i} \text { (est) }}$ for all points during the test-cycle, the estimated terminal voltage curve is compared to the measured terminal voltage curve using the correlationfactor $r^{2} . \tau$ is then manually adjusted to maximise $r^{2}(>0.995)$. In the battery parameter estimator spreadsheet $\mathrm{OCV}_{0}, \mathrm{OCV}^{\prime}, \mathrm{R}_{0}$ and $\mathrm{R}_{\mathrm{P}}$ are calculated with the Excel $^{\circledR}$ function LINEST. LINEST is a multiple linear regression formula using the $\mathrm{I}_{\mathrm{P}}, \mathrm{I}_{\mathrm{L}},\left(\Sigma \mathrm{I}_{\mathrm{L}} \Delta \mathrm{t}\right)$ vectors.

The work presented in the next section expands this calculation method with the ability to automatically adjust the value of $\tau$ according to the sum of the squared errors $\Delta \mathrm{V}_{\mathrm{i}}$. This new procedure is written in the Matlab $^{\circledR}$ environment allowing the procedure to be modified to suit different schemes.

\section{Adjusted calculation method}

\subsection{Scheme}

The preliminary scheme used to accommodate these updates to the NREL calculation method is the same as the scheme shown in Figure 5.

\subsection{Calculation method in Matlab}

The calculation method implemented in Matlab will now be outlined.

The accuracy (value of the sum of the squared terminal-voltage errors) and $\tau$ are set at a desired starting value.

Acquired data from the Digatron is imported in the Matlab procedure, this data consists of the time vector $T$, load-current vector $I_{L}$ and the terminal-voltage vector $\mathrm{V}_{\mathrm{L}}$. This data is used to calculate the polarization-current vector $\mathrm{I}_{\mathrm{P}}$ with the help of the Runga Kutta II method [2]. Using this calculated data and the imported data from the Digatron, the procedure is able to calculate $\mathrm{OCV}_{0}, \mathrm{OCV}^{\prime}, \mathrm{R}_{\mathrm{P}}$ and $\mathrm{R}_{0}$ with the multiple linear regression formula of Matlab. All imported and calculated data is used to produce the terminalvoltage vector $\mathrm{V}_{\mathrm{L} \text {,(est.). }} \mathrm{V}_{\mathrm{L} \text {,(est.) }}$ is subtracted from $V_{L}$ to calculate the terminal-voltage error vector $\Delta \mathrm{V}$.

In the final step of the procedure $\mathrm{I}_{\mathrm{P}}, \mathrm{I}_{\mathrm{L}}, \mathrm{V}_{\mathrm{L} \text {,(est.) }}, \mathrm{V}_{\mathrm{L}}$ and $\Delta \mathrm{V}$ are plotted and presented to the user together with various statistical information and the values for $\tau, \mathrm{OCV}_{0}, \mathrm{OCV}^{\prime}, \mathrm{R}_{\mathrm{P}}, \mathrm{R}_{0}$. An example of these outputs is presented in section 4
(Test results) of the paper.

Once the first iteration cycle has been completed, the value of the accuracy is adjusted to further refine the value of $\tau$ and to maximise $r^{2}$.

\section{Test results}

\subsection{Test results with FreedomCAR calculation spreadsheet}

As an example for the FreedomCAR calculation spreadsheet, the test-data of a lithium battery are represented. The data were recorded during a testcycle $^{2}$ where the lithium-battery (producer's data sheet for the battery shown in table 2) was submitted to a discharge-current of $40 \mathrm{~A}$ and a charge-current of $15 \mathrm{~A}$, with a rest-period in between. Input-data for the spreadsheet were imported from the recorded data. The Input-data consisted of the time-vector, the load-current vector and the terminal-voltage vector.

Table 2: Data-sheet for the tested battery

\begin{tabular}{|l|c|}
\hline Battery voltage & $3.2 \mathrm{~V}(2.1 \ldots 3.65 \mathrm{~V})$ \\
\hline Capacity & $10 \mathrm{Ah}$ \\
\hline Constant discharge current & $120 \mathrm{~A}$ cont. \\
\hline Maximum discharge current & $140 \mathrm{~A} 18 \mathrm{~s}$ \\
\hline Maximum charge current & $30 \mathrm{~A}$ \\
\hline Internal resistance & $\begin{array}{c}6 \mathrm{~m} \Omega(>1000 \\
\text { cycles })\end{array}$ \\
\hline Mass & $400 \mathrm{~g}$ \\
\hline Dimensions & $138-40-40 \mathrm{~mm}$ \\
\hline
\end{tabular}

Table 3 presents the calculated results from the FreedomCAR spreadsheet. The table is automatically generated by the LINEST Function used in the spreadsheet. $\tau$ has in this case a chosen value of $11,42 \mathrm{sec}$. The calculated values for $\mathrm{OCV}_{0}$, OCV', $R_{\mathrm{P}}$ and $\mathrm{R}_{0}$ (as seen in row 5 of table 3 ) are $3,34 \mathrm{~V}, \quad 3,2 \mathrm{Asec} / \mathrm{V}, \quad 1,88 \mathrm{~m} \Omega$ and $4,64 \mathrm{~m} \Omega$ respectively. $\mathrm{r}^{2}$ is for the chosen value of $\tau$ equal to 0,995 . Row 6 in table 3 represents the standarddeviation on the respective values in row 5 of table 3.

2 The test-cycle values for current and rest-period where in accordance with the FreedomCAR requirements 
Table 3: Test-results from the FreedomCAR spreadsheet

\begin{tabular}{|c|c|c|c|}
\hline$\tau$ & 11,42 & & \\
\hline$r^{2}$ & 0,995 & & \\
\hline \multicolumn{4}{|c|}{ Regression analysis } \\
\hline $\mathrm{OCV}^{\prime}$ & $\mathbf{R}_{\mathbf{p}}$ & $\mathbf{R}_{\mathbf{0}}$ & $\mathrm{OCV}_{0}$ \\
\hline $3,20 \mathrm{E}-05$ & $1,88 \mathrm{E}-03$ & 4,64E-03 & $3,34 \mathrm{E}+00$ \\
\hline $2,45 \mathrm{E}-06$ & $3,56 \mathrm{E}-05$ & $3,10 \mathrm{E}-05$ & $1,48 \mathrm{E}-03$ \\
\hline
\end{tabular}

The graph in figure 6 shows the measured terminal-voltage $\mathrm{V}_{\mathrm{L}}$ versus the estimated terminal-voltage curve $\mathrm{V}_{\mathrm{L} \text { (est.). }}$.

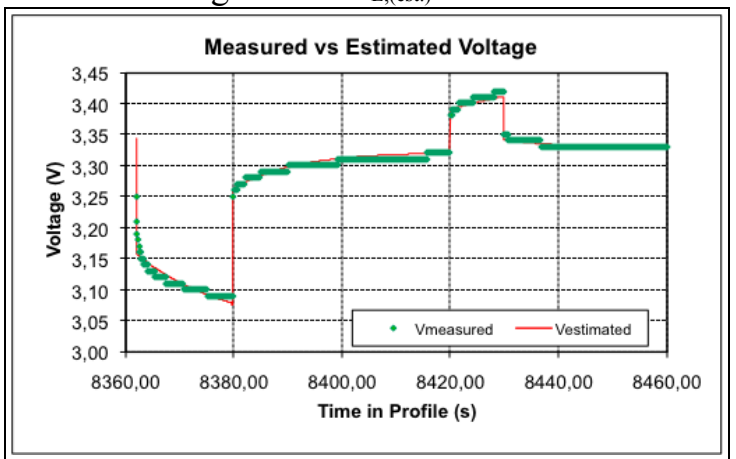

Figure 6: $\mathrm{V}_{\mathrm{L}}$ versus $\mathrm{V}_{\mathrm{L} \text {,(est.) }}$

Figure 7 shows $\Delta V_{L}$ ( Error in estimated terminal-voltage) in function of time.

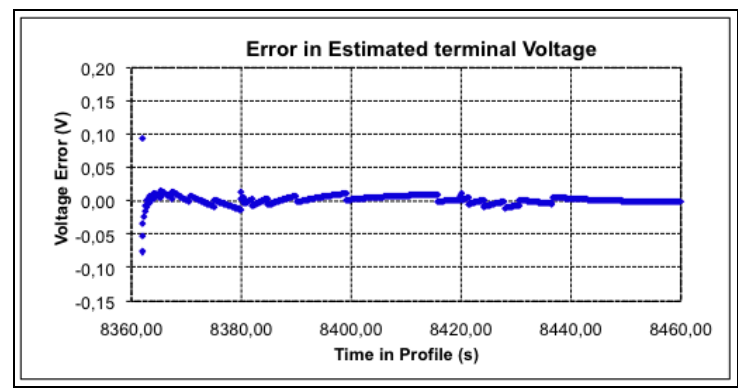

Figure 7: Error in Estimated terminal Voltage

\subsection{Test results with adjusted calculation method}

The same imported data as for the FreedomCAR calculation spreadsheet were used in this adjusted calculation method. For $\tau$ a start-value of $5 \mathrm{sec}$ was chosen and for the accuracy 0,04. Output data from the Matlab procedure where as follows.

First part: regression data
Table 4: Test-results from the adjusted calculation method

\begin{tabular}{|c|c|c|c|}
\hline$\tau$ & 11,420 & \multirow{3}{*}{ Regression analysis } \\
\cline { 1 - 2 } $\mathrm{r}^{2}$ & 0,9956 & $\mathbf{R}_{\mathbf{0}}$ & $\mathbf{O C V}_{\mathbf{0}}$ \\
\cline { 1 - 2 } $\mathbf{O C V}^{\prime}$ & $\mathbf{R}_{\mathbf{p}}$ & $4,73 \mathrm{E}-03$ & $3,35 \mathrm{E}+00$ \\
\hline $3,99 \mathrm{E}-05$ & $1,80 \mathrm{E}-03$ & $2,84 \mathrm{E}-05$ & $1,37 \mathrm{E}-03$ \\
\hline $2,26 \mathrm{E}-06$ & $3,25 \mathrm{E}-05$ &
\end{tabular}

Second part: graphical output

The graphical output presents various calculated and imported parameters of the adjusted calculation method in function of time.

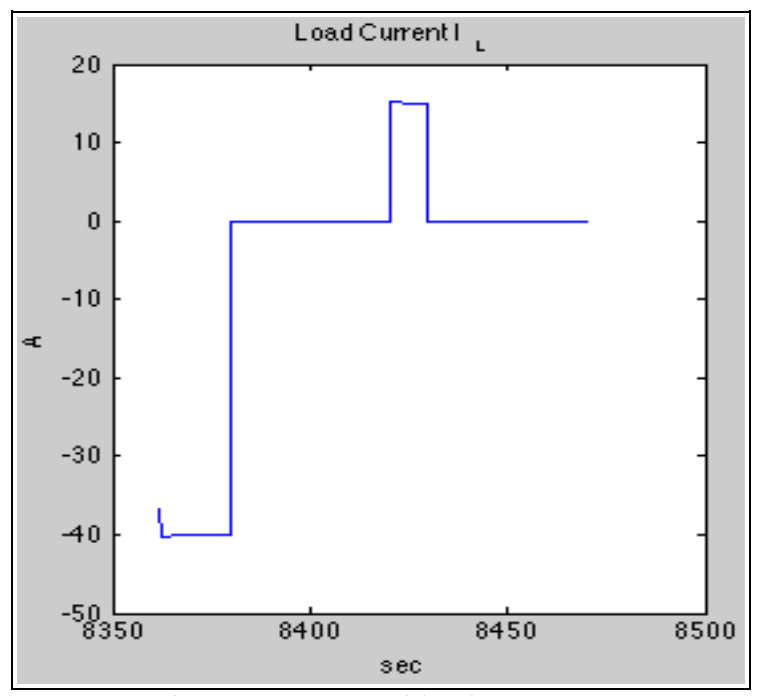

Figure 8: Measured load-current $\mathrm{I}_{\mathrm{L}}$

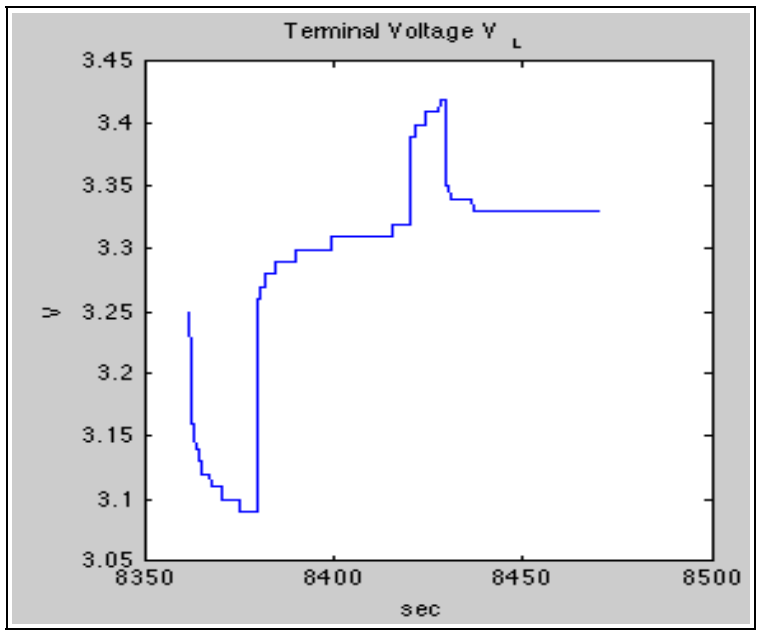

Figure 9: Measured terminal-voltage $\mathrm{V}_{\mathrm{L}}$ 


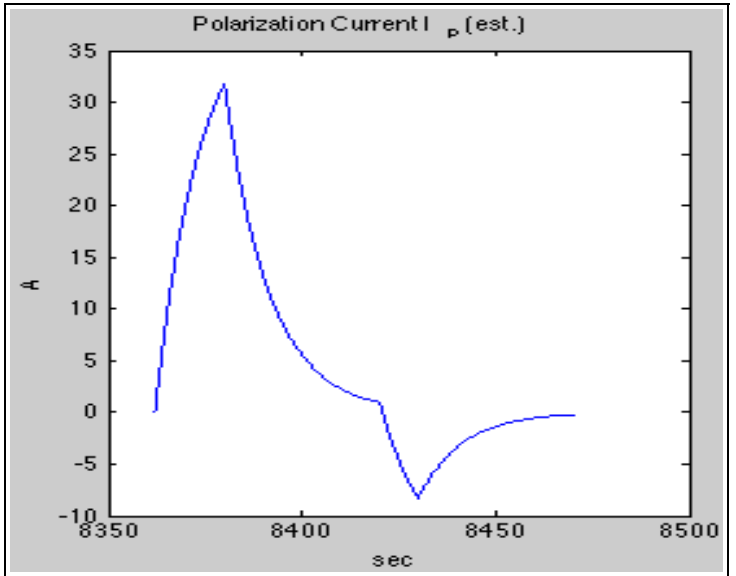

Figure 10: Calculated polarization-current $\mathrm{I}_{\mathrm{P}}$ using Runga Kutta II method

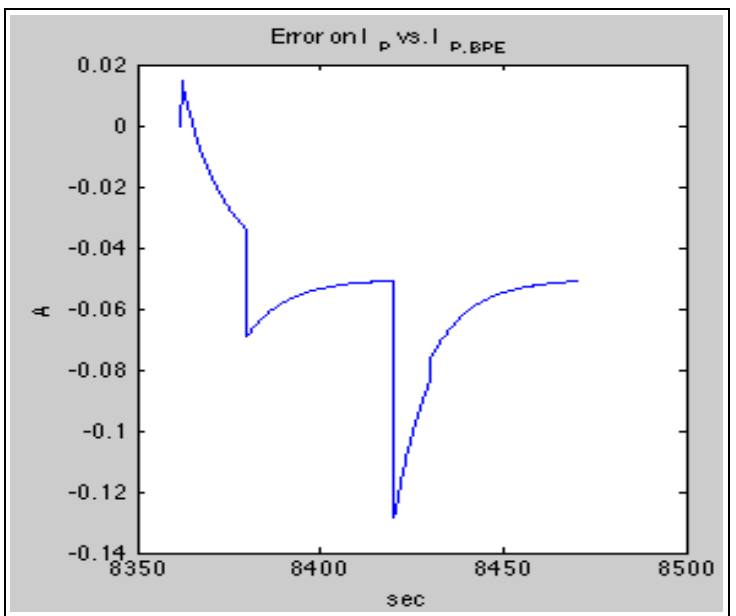

Figure 11: Error on $\mathrm{I}_{\mathrm{P}}$ calculated with the Runga Kutta II method vs. $I_{P, B P E}$ calculated using equation 3

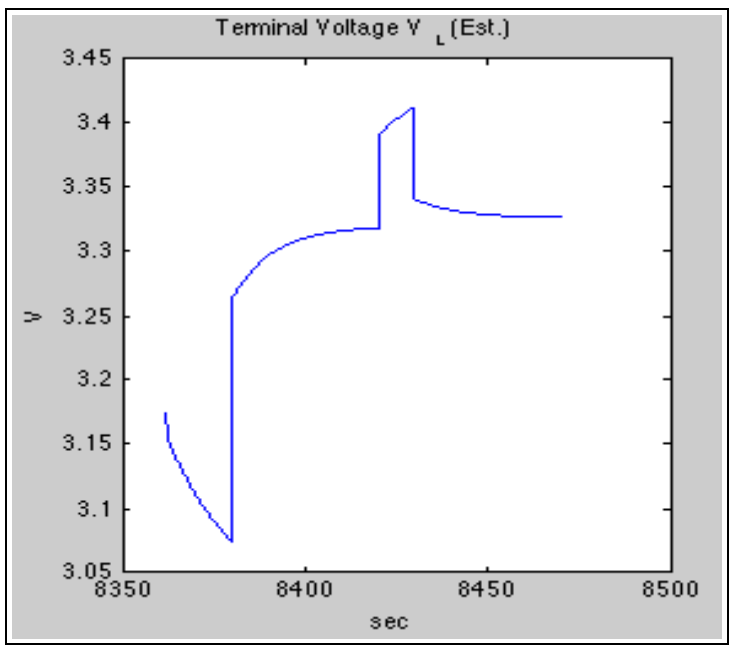

Figure 12: Calculated terminal-voltage $\mathrm{V}_{\mathrm{L} \text {,(est.) }}$ using polarization-current $I_{P}$ calculated with the Runga Kutta II method

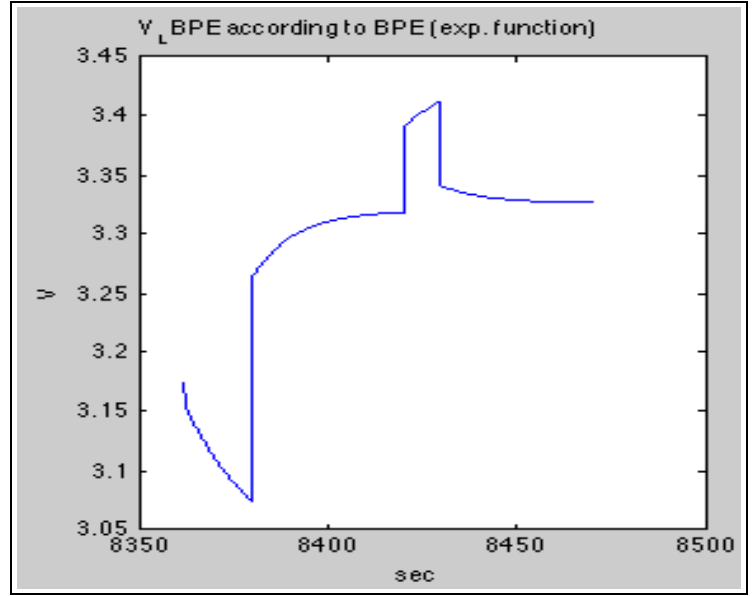

Figure 13: Calculated terminal-voltage $\mathrm{V}_{\mathrm{L}, \text { (est.)BPE }}$ using polarization-current $I_{P}$ calculated with equation 3

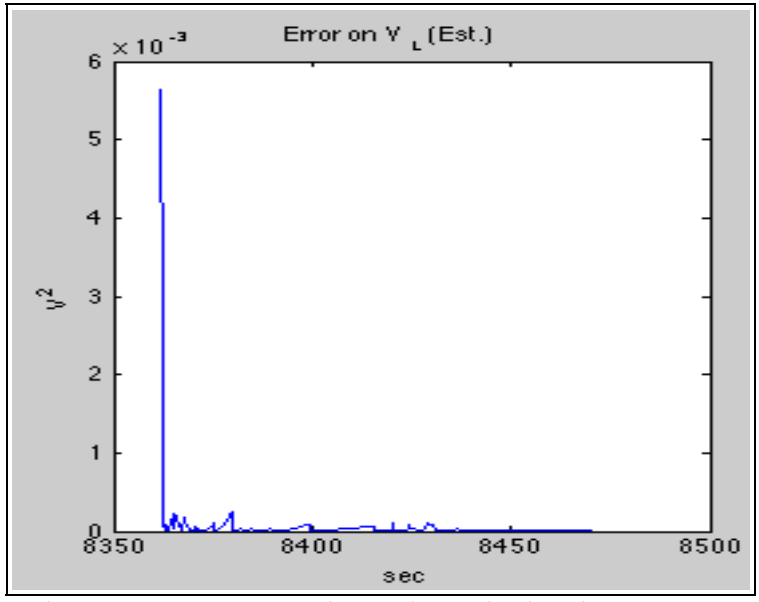

Figure 14: Error on estimated terminal-voltage $\mathrm{V}_{\mathrm{L} \text {,(est.). }}$. Error on $\mathrm{V}_{\mathrm{L}, \text { (est.) }}=\mathrm{V}_{\mathrm{L}}-\mathrm{V}_{\mathrm{L} \text {,(est.) }}$

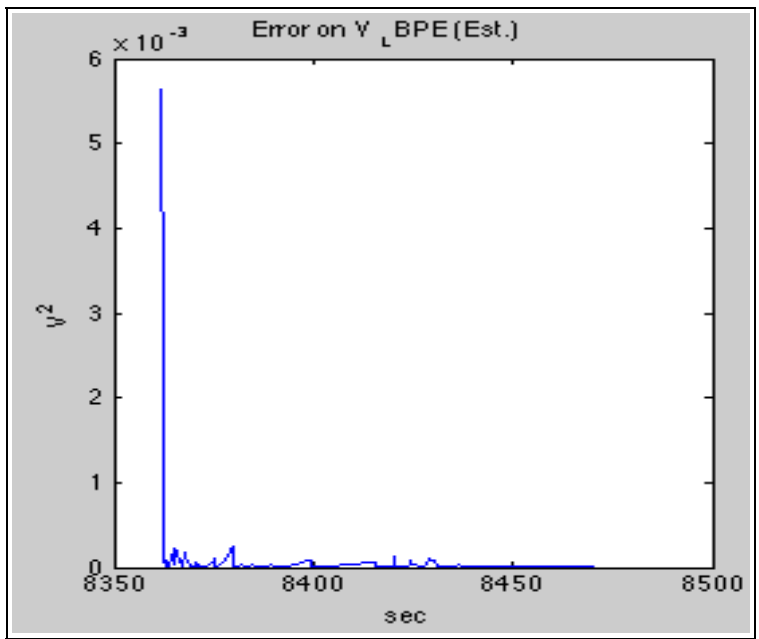

Figure 15: Error on estimated terminal-voltage $\mathrm{V}_{\mathrm{L}, \text { (est.)BPE. }}$. Error on $\mathrm{V}_{\mathrm{L},(\text { est.)BPE }}=\mathrm{V}_{\mathrm{L}}-\mathrm{V}_{\mathrm{L}, \text { (est.)BPE }}$ 


\subsection{Comparison of the test methods}

\subsubsection{Comparison of the regression data}

Table 5 displays the regression data for the FreedomCAR calculation method and the adjusted calculation method.

Table 5: Comparison of the regression data

\begin{tabular}{|c|c|c|c|}
\hline \multicolumn{4}{|c|}{ Regression analysis for FreedomCAR method } \\
\hline $\mathbf{O C V}^{\prime}$ & $\mathbf{R}_{\mathbf{p}}$ & $\mathbf{R}_{\mathbf{0}}$ & $\mathbf{O C V}_{\mathbf{0}}$ \\
\hline $3,20 \mathrm{E}-05$ & $1,88 \mathrm{E}-03$ & $4,64 \mathrm{E}-03$ & $3,34 \mathrm{E}+00$ \\
\hline $2,45 \mathrm{E}-06$ & $3,56 \mathrm{E}-05$ & $3,10 \mathrm{E}-05$ & $1,48 \mathrm{E}-03$ \\
\hline \multicolumn{5}{|c|}{ Regression analysis for Adjusted method } \\
\hline OCV $^{\prime}$ & $\mathbf{R}_{\mathbf{p}}$ & $\mathbf{R}_{\mathbf{o}}$ & $\mathbf{O C V}_{\mathbf{0}}$ \\
\hline $3,99 \mathrm{E}-05$ & $1,80 \mathrm{E}-03$ & $4,73 \mathrm{E}-03$ & $3,35 \mathrm{E}+00$ \\
\hline $2,26 \mathrm{E}-06$ & $3,25 \mathrm{E}-05$ & $2,84 \mathrm{E}-05$ & $1,37 \mathrm{E}-03$ \\
\hline
\end{tabular}

OCV', $\mathrm{R}_{\mathrm{P}}, \mathrm{R}_{0}, \mathrm{OCV}_{0}$ calculated with the FreedomCAR calculation method and the adjusted calculation method all correspond in magnitude and standard-deviation. The difference between both calculations is presented in table $6 . \triangle \mathrm{OCV}^{\prime}$ is the largest difference of all calculated parameters, by taking the standarddeviations on $\mathrm{OCV}^{\prime}$ in to account $\triangle \mathrm{OCV}^{\prime}$ can be reduce to $-2,85 \mathrm{E}-06$ or $9 \%$ difference.

Comparing the regression data from the adjusted calculation method with the FreedomCAR calculation method revealed a strong correlation. With this in mind, the Matlab procedure can be adapted for other RESS-models.

Table 6: Difference between calculation methods

\begin{tabular}{|c|c|c|c|c|}
\cline { 2 - 5 } \multicolumn{1}{c|}{} & $\mathbf{O C V}^{\prime}$ & $\mathbf{R}_{\mathbf{p}}$ & $\mathbf{R}_{\mathbf{0}}$ & $\mathbf{O C V}_{\mathbf{0}}$ \\
\hline$\Delta$ & $-0,79 \mathrm{E}-05$ & $0,08 \mathrm{E}-03$ & $-0,09 \mathrm{E}-03$ & $-0,01 \mathrm{E}-03$ \\
\hline in $\%$ & 24 & 4 & 2 & 0,3 \\
\hline
\end{tabular}

\subsubsection{Comparison of the calculated terminal-voltage $V_{L,(e s t .)}$ versus $V_{L}$}

Figure 9 represents the measured terminalvoltage $\mathrm{V}_{\mathrm{L}}$ in function of time. Comparing this curve with the graph shown in figure 12 reveals a similar plot. This means that the adjusted calculation method can simulate the response of the battery's terminal-voltage $V_{L}$ in a satisfying way. Supporting this fact is the magnitude of the error on $\mathrm{V}_{\mathrm{L} \text {, (est.) }}$ (compared to $\mathrm{V}_{\mathrm{L}}$ ), represented in figure 14. In figure 14 a steep decline of the error is noted after the initial part of the test. Even in the initial part the error on the terminal-voltage is small in comparison with the terminal voltage $\mathrm{V}_{\mathrm{L}, \text { (est.) }}$ (peaking at 5,7E-03V).

Since equation 3 was already implemented in the Matlab procedure to compare the polarizationcurrent $I_{P}$ (figure 11) with the polarization-current calculated with the Runga Kutta II method (figure 10 ), $\mathrm{V}_{\mathrm{L}, \mathrm{BPE}}$ was calculated and plotted (see figure 13). The curve plotted in figure 13 correlates to the curves of figure 12 and figure 9, meaning that the FreedomCAR calculation method can simulate the response of the battery's terminal-voltage $\mathrm{V}_{\mathrm{L}}$ in the same accurate way as the adjusted calculation method. The error on the terminal-voltage $\mathrm{V}_{\mathrm{L}, \mathrm{BPE}}$ compared to the terminal-voltage $\mathrm{V}_{\mathrm{L}}$ is presented in figure 15. Remarks on this graph are the same as the remarks made on figure 14 (stated in 4.3.2 paragraph 1).

\subsubsection{Adjusted calculation model applied on Thevenin battery model}

As an example for the adjusted calculation method, the parameters for the Thevenin battery model are calculated using the data from the previous test. The Thevenin battery model is shown in figure 16 .

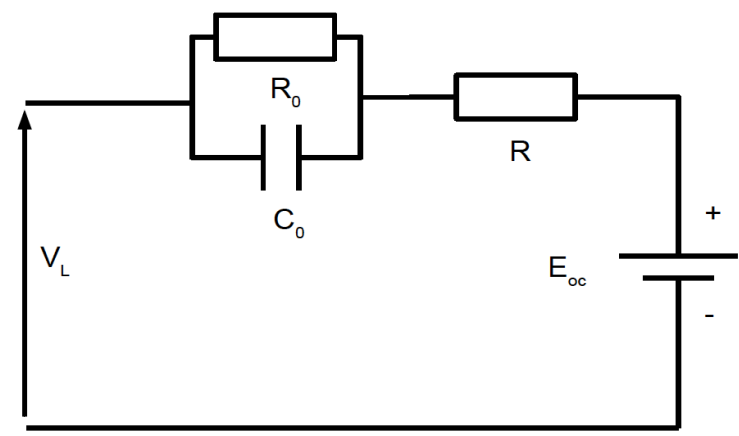

Figure 16: Thevenin battery scheme

The regression data calculated by the Matlab procedure for the Thevenin model are given in table 7 .

Table 7: Regression data for Thevenin model

\begin{tabular}{|c|c|c|}
\hline$\tau$ & 14,13 \\
\cline { 1 - 2 } $\mathrm{r}^{2}$ & 0,9950 & \\
\multicolumn{3}{|c|}{ Regression analysis } \\
\hline $\mathbf{R}[\boldsymbol{\Omega}]$ & $\left.\mathbf{R}_{\mathbf{0}} \boldsymbol{\Omega}\right]$ & $\mathbf{E}_{\mathbf{o c}}[\boldsymbol{\Omega}]$ \\
\hline $4,41 \mathrm{E}-03$ & $2,32 \mathrm{E}-03$ & $3,33 \mathrm{E}+00$ \\
\hline $1,41 \mathrm{E}-05$ & $2,46 \mathrm{E}-05$ & $2,19 \mathrm{E}-04$ \\
\hline
\end{tabular}

Calculation of the terminal-voltage $V_{L}$ is 
represented in figure 17 where $\mathrm{V}_{\mathrm{L}}$ is plotted in function of time. The equation 7 was used to calculate $\mathrm{V}_{\mathrm{L}}$. In equation 7 is $\mathrm{I}_{0}$ the current passing through $\mathrm{R}_{0}$ and $\mathrm{I}_{\mathrm{L}}$ the current through the battery's terminal connectors.

$$
V_{L, i(e s t)}=E_{o c}-I_{L, i} \cdot R-I_{0, i} \cdot R_{0}
$$

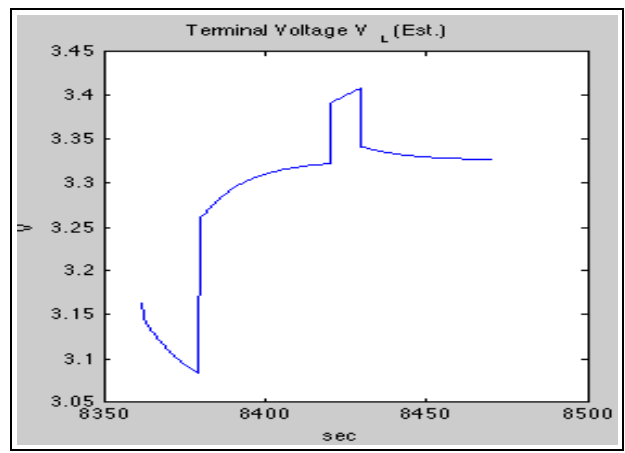

Figure 17: Calculated terminal-voltage $\mathrm{V}_{\mathrm{L}}$ using equation 7

\section{Conclusions}

Adjusting the FreedomCAR calculation method and writing the calculation procedure in the Matlab environment, enabled the creation of a more flexible and accurate way of calculating the magnitudes of the RESS model's components. Adapting the procedure to fit other models (schemes) can now be done with the adjusted calculation method as a reference procedure, giving the opportunity to expand the procedure to many more models. Expanding the procedure to fit more models is part of the future research as is the adaptation of the models to suit different load-conditions.

\section{Acknowledgments}

Via this way I want to express my gratitude for the help received from the co-authors, ir. Marc Borremans and especially from my colleague ing. Tim De Troyer for his help with Matlab.

\section{References}

[1] U.S. DEPARTMENT OF ENERGY. FreedomCAR Battery Test Manual For Power-Assist Hybrid Electric Vehicles. IDAHO, Assistant Secretary for Energy Efficiency and Renewable Energy (EE), 2003

[2] LACOR (C.). Basistechnieken voor Computersimulaties, Vrije Universiteit Brussel, Course 2BA, Vubpers, 2008
[3] Zoroofi (S.), Modelling and simulation of vehicular power systems. Master dissertation, dept. Energy and Environment, Chalmers university of technology, Sweden, 2008

[4] Culcu (H.). Karakterisatie van lithium batterijen: Experimenteel bepaalde celparameters van lithium-ion batterijen met FreedomCAR model, Vrije Universiteit Brussel (VUB) dept. ETEC, 2008

[5] VAN MIERLO (J.), VAN DEN BOSSCHE (P.), MAGGETTO (G.). Models of energy sources for EV and HEV: fuel cells, batteries, ultracapacitors, flywheels and enginegenerators. Journal of power sources, Elsevier, 2003

[6] HALPER (M.S.), ELLENBOGEN (J.C.). Supercapacitors: A Brief Overview. Mitre Nanosystems Group, Virginia, 2006

[7] JOHNSON (V. H.), PESARAN (A. A.). Temperature-Dependent Battery Models for High-Power Lithium-Ion Batteries. $17^{\text {th }}$ Electric Vehicle Symposium. Montreal, 2000, pp. 2-4

[8] INTERNATIONAL STANDARD. IEC 61982-2. Secondary Batteries for the propulsion of electric road vehicles, 2002

[9] TARASCON (J.-M.), ARMAND (M.). Issues and challenges facing rechargeable lithium batteries In: Nature, 2001, vol 414, 15 nov 2001, pp. 359-366

[10] JACKEY (R.A.). A Simple, Effective LeadAcid Battery Modeling Process for Electrical System Component Selection. The MathWorks, Inc, 2007

[11] VAN DEN BOSSCHE (P.), VREVEN (K.). Comparative modelling of traction batteries in view of electric vehicle applications. 22 $2^{\text {th }}$ Electric Vehicle Symposium. Yokohama, 2006, pp. 626-633

[12] MARKEL (T.), et al. Advisor: a systems analysis tool for advanced vehicle modelling, Journal of Power Sources, Elsevier, 2002, pp. 255-266

[13] JOSSEN (A.). Fundamentals of battery dynamics, Journal of Power Sources, Elsevier, 2006, pp. 530-538

[14] RODRIGUES (S.), MUNICHANDRAIAH (N.), SHUKLA (A.K.). A review of state-ofcharge indication of batteries by means of a.c. impedance measurements, Journal of Power Sources, Elsevier, 2000, pp. 12-20

[15] KNAUFF (M.), DAFIS (J.), NIEBUR (D.), KWATNY (H.), NWANKPA (C.), McLAUGLIN (J.), SINGH (P.). Simulink 
Model for Hybrid Power System Test-bed. Paper Accepted for Publication in Proceedings of IEEE Electric Ship Technologies Symposium, Arlington, 2007

[17] ABU-SHARKH (S.), DOERFFEL (D.). Rapid test and non-linear model characterisation of solid-state lithium-ion batteries, Journal of Power Sources, Elsevier, 2004, pp. 266-274

[18] JOHNSON (V.H.). Battery performance models in ADVISOR. Journal of Power Sources, Elsevier, 2002, pp. 321-329

\section{Author}

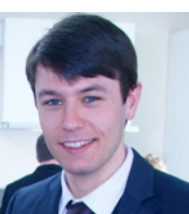

Bavo Verbrugge graduated as a Master in industrial engineering in 2007. At this time he works as a $\mathrm{PhD}$. candidate at the free University of Brussels (VUB), where he's currently performing research on integrated modelling of batteries and EDLC's.

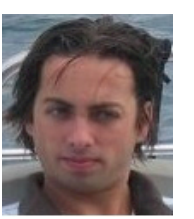

Yves Heremans graduated as a Master in industrial engineering in 2007. At this time he studies civil engineering at the free University of Brussels (VUB), where he's currently working on his master thesis on integrated modelling of batteries and EDLC's.

Frederik Van Mulders graduated in 2005 as a Mechanical Industrial Engineer at the Erasmus University College Brussels and was invited to

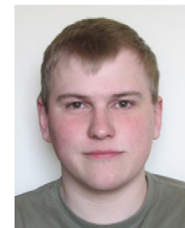

be a PhD student at the ETECdepartment for the Vrije Universiteit Brussel and the Erasmus University College Brussels. There, his main research covers supercapacitor based peak power units.

Hasan CULCU (born in Isparta, Turkey, 1982) obtained his B.S. and M.S. degree in Mechanical and Electrical Engineering at Vrije Universiteit Brussel, where he is doing now his research concerning energy storage systems and simulations of hybrid vehicles.

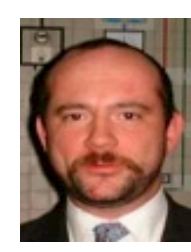

He graduated as civil mechanicalelectrotechnical engineer from the Vrije Universiteit Brussel and defended his $\mathrm{PhD}$ at the same institution with the thesis

"The Electric Vehicle: raising the standards". He is currently lecturer at the engineering faculties of the Erasmushogeschool Brussel and the Vrije Universiteit Brussel, and in charge of co-ordinating research and demonstration

projects for electric vehicles in collaboration with the international associations CITELEC and AVERE. His main research interest is electric vehicle standardization, in which quality he is involved in international standards committees such as IEC TC69, of which he is Secretary, and ISO TC22 SC21.

Joeri van Mierlo received M.S. and $\mathrm{PhD}$ degree in electromechanical engineering from Vrije Universiteit Brussel in 1992 and 2000 with greatest distinction. From 2004 he has been appointed as a fulltime professor at the Vrije Universiteit Brussel. Currently his research is devoted to the

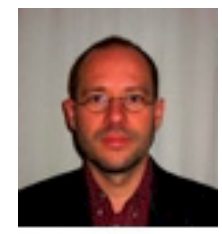
development of hybrid propulsion (converters, supercaps, energy management, etc.) systems as well as to the environmental comparison of vehicles with different kind of drive trains and fuels. 